\title{
Digital Economy, Industrial Structure Upgrade and Economic High-Quality Development:An Empirical Research Based on the Mediation Effect Model
}

\author{
$\mathrm{Xu}$ Xiaohui and Liao Han \\ (School of Economics, Zhongnan University of Economics and \\ Law;2352467389@qq.com)
}

\begin{abstract}
Based on panel data of 31 provincial-level administrative units (excluding Hong Kong, Macao and Taiwan) in China from 2015 to 2019, using fixed effect model and mediation effect model, this paper makes an empirical analysis on the interaction among digital economy, industrial structure upgrade and high-quality economic development. The results show that, from the overall effect, the digital economy can significantly promote the high-quality development of the economy, and there are regular regional differences, and the relationship between the promotion intensity and the development level of the digital economy is proportional. From the mediation effect, in the relationship between digital economy and high-quality economic development, the upgrade of industrial structure has played a significant part of the mediation effect, the proportion of mediation effect is $25.17 \%$. In addition, the mediation effect of industrial structure upgrade has obvious regional difference, the western area is the strongest, the eastern area is the second, the central area is the weakest. Based on the above research,the concrete policy suggestions are given to promote the development of digital economy and upgrade the level of industrial structure to promote the high-quality development of economy.
\end{abstract}

Keywords:Digital Economy; Industrial Structure Upgrade; High-Quality Economic Development; Mediation Effect Model

\section{Introduction}

Since the reform and opening-up, china's economy has developed rapidly, its economic aggregate ranks second in the world, and its per capita income has reached the standard of middle-and high-income countries. However, it is difficult to carry on with the extensive development model for a long time, in which the extensive development model is realized by the input of capital, labor force, resources and other factors. However, this traditional extensive development model has brought a series of problems, such as serious environmental pollution, widening income gap, some industries overcapacity and so on, these problems have a negative impact on the further development of china's economy. In this context, General Secretary Xi Jinping made an important assertion in his report to the 19th CPC National Congress that "China's economy has transitioned from a stage of high-speed growth to a stage of high-quality development. ". The most distinctive feature of china's economy in the new era is high-quality development. He stressed that our current and future macroeconomic regulation and control must be based on the fundamental requirement of high-quality economic development. We can see that high-quality economic development has risen to the level of national strategy, it occupies a very important position and role in the process of economic development in china. In addition, once the digital economy is integrated into society, the impact it will have on people, society, and the world is enormous. With china's economic development into a new era, how to achieve high-quality economic development has become an important 
topic of public concern. To this end, china urgently needs new drivers of high-quality economic development.

At present, the most mature and widely used emerging technology is represented by Internet technology, thus a series of emerging economic forms, such as digital economy, have come into being. china attaches great importance to the driving role of digital economy in economic and social development. The 2019 Central Economic Work Conference stressed that its basic task is to focus on promoting high-quality development and vigorously developing the digital economy, which can provide a direction for transforming the pattern of economic growth. The digital economy has been able to breathe new life into economic development and social stability. China's digital economy reached 31.3 trillion yuan in 2018, accounting for 34.8 percent of GDP, according to the white paper on china's digital economy development and employment released by the information and communications research Institute there are 191 million jobs in the digital economy, accounting for 24.6 percent of total employment. In 2020, china's total digital economic value added reached 39.2 trillion yuan, accounting for 38.6 percent of GDP. It can be seen from this, our country's digital economy development presents the situation is the high quality, the high growth speed. The digital economy takes many forms, such as digital labor. The digital economy, as a new dynamic, is the most dynamic. The digital economy can also reflect the future direction of industrial development.The digital economy is an inevitable trend of social development. The vigorous development of digital economy affects the way of production and life of human beings. China is not only a big country in the world network, but also a big country in the digital economy, in the context of the new concept of innovative, coordinated, green, open and shared development, it is actively promoting digital industrialization and industrial digitalization, and also accelerating the deep integration of the real economy and the digital economy, to promote high-quality economic development. Looking to the future, let the digital economy, the new engine of sustainable and healthy development, play its role in driving high-quality economic development.

The upgrade of industrial structure is a long-term goal to basically realize socialist modernization. Under china's new development pattern, industrial structure upgrade is an important strategic measure to realize high-quality economic development. Through optimizing the allocation of factor resources, the upgrade of industrial structure promotes the flow of production factors to high value-added sectors, realizes the rational distribution of production factors among sectors, and thus affects the high-quality development of economy. At the fourth plenary session of the 19th central committee of the CPC, it was pointed out that the key to promoting high-quality economic development in the new era is to transform the driving force of development, while the upgrade of industrial structure is the key to transform the driving force of development. However, the output level and quality level of different industrial structure are different in the process of economic development. The structure of social demand will change with the change of economic development, which causes the mismatch between the structure of social supply and the structure of social demand. At this point, the industrial structure needs to be adjusted, so that the allocation of social resources in various sectors and sectors more effective, the allocation of resources to improve the efficiency of units. The upgrade of industrial structure is a transition from low-efficiency production to high-efficiency production, which leads to the inflow of high-efficiency production sectors into human and capital, thus making the optimal allocation of resources more reasonable and boosting the high-quality development of economy. It can be seen that the industrial structure 
upgrade has important practical significance on the impact of high-quality economic development. Therefore, it is of great significance and research value to study the relationship among digital economy, industrial structure upgrade and high-quality economic development.

\section{Literature Review}

\subsection{Digital Economy and High-Quality Economic Development}

In recent years, with the rapid development of digital economy, the relationship between digital economy and high-quality economic development has been highly valued by scholars. At present, the paper mainly studies the influence of digital economy on high-quality economic development from two aspects: theoretical research and empirical research. In terms of theoretical research, such as Wen Jun and others (2020) believe that digital economy has promoted high-quality transformation of many economic dimensions from three aspects: upgrading the quality of traditional factors, accelerating the efficiency of resource allocation and shaping the new momentum of data factors. Sheng Lei (2020) proposed the digital economy to promote the industry high quality development main implementation path [6].Zhou Qingxiang and he aiping (2020) believe that the development of digital economy provides an important opportunity to promote the high-quality development of the Yellow River Basin. Shi Bo (2020) believes that the digital economy drives the high-quality development of urban economy by perfecting the Industrial System of digital development, optimizing the digital development environment and constructing the path of digital governance system. According to Li Hui (2020), digital economy is the new driving force of high-quality development of china's macro-economy, and also brings new opportunities for high-quality development of china's enterprises. Wang Juan (2019) discusses the relationship between high-quality economic development and digital economy and the internal mechanism of promoting high-quality economic development from the following aspects: the evolution difference of factor allocation transformation, the evolution of economic growth quality and the evolution of industrial upgrading. Ding Zhifan (2020) investigates the impact of digital economy on high-quality economic development on the micro, medium and macro levels. Yang Hutao (2020) believes that the new generation of digital economy 2.0 needs to guide the innovation field and development direction of digital economy through institutional innovation, to make it from small-scale, narrow-domain service industry to local prosperity to large-scale, multi-domain industry penetration, as an engine to promote high-quality development [12]. As for empirical research, Wei zhuangyu and others (2021) hold that the digital economy plays a significant role in promoting the high-quality development of the manufacturing industry, and has become an important driving force in promoting the high-quality development of the manufacturing industry in China. According to Tang yy-chyou (2020), smart city construction, as an agent variable of digital economy, can promote high-quality economic development. Ningchaoshan (2021) believes that the digital economy has a significant positive effect on high-quality economic development. Zhao Tao et Al. (2020) used panel data from 222 cities at prefecture level and above in China from 2011 to 2016 to find that the digital economy significantly promotes high quality development.

\subsection{Digital Economy and Upgrade of Industrial Structure}

At present, the research on digital economy is at the initial stage, and the concept definition, measurement, statistical classification and comprehensive evaluation index 
system involved are not yet mature, therefore, there are few theoretical and empirical studies on the relationship between digital economy and industrial structure upgrading. Some scholars think that digital economy has promoted the upgrading of industrial structure. For example, Zhang Yuzhe (2018) thinks that the development of digital economy has promoted the realization of leapfrog development of industrial structure in China. Lin Yuhao and Chen Yingkui (2020) found that the digital economy can significantly promote the upgrading of industrial structure from the perspective of factor flow. Li Xiaozhong and Wu Jia-xu (2020) found that the digital economy and its sub-systems have a positive effect on the transformation and upgrading of China's industrial structure. Wang Kai (2021) found that the development of the digital economy can promote the optimization and upgrading of industrial structure by enhancing the capacity of capital and labor allocation. Chen Xiaodong and Yang Xiaoxia (2021) believe that the digital economy is the new driving force of industrial structure upgrading in the future. Li Yingjie and Han Ping (2021) used panel data from 30 provinces and cities in China from 2012 to 2018, and found that the development of digital economy can promote the optimization and upgrade of industrial structure, at the same time, the influence of the development of digital economy on the industrial structure has certain regional difference. Jiao Shuaitao and Sun Qiubi (2021) using panel data from 30 provinces and cities in China from 2013 to 2019 , they found that the development of digital economy can promote the upgrade of industrial structure through promoting regional innovation. Some scholars also believe that the digital economy has affected the structural upgrade of the manufacturing industry, such as Shen Yunhong and Huang Heng (2020), using panel data from Zhejiang Province from 2008 to 2017, the sub-factors of digital economy will influence the upgrade of industrial structure of traditional manufacturing industry. In addition, some scholars believe that the digital economy affects the supply-side restructuring. He Da'an and Xu Yifan (2020) hold that the process of industrial structure change and the process of supply-side structural reform remolding are synchronous, and the digital economy changes with the process of supply-side structural reform remolding.

\subsection{Upgrade of the Industrial Structure and High-Quality Economic Development}

There is relatively little literature on the impact of industrial structure upgrading on high-quality economic development, but generally speaking, scholars still generally believe that industrial structure upgrading promotes high-quality economic development, for example, Zhu Fenghui and Liu Lifeng (2020) used panel data from 2003 to 2016 for 230 cities at and above the prefecture level in China. Using China's provincial panel data from 2000 to 2017, Shi Dan et Al (2020) found that changes in the industrial structure as a whole are conducive to promoting China's high-quality development, and that the transformation and upgrading of the industrial structure has a "structural dividend" on China's economic growth, total factor productivity helps drive green growth, but to some extent it will divide China's regional economy. Some scholars believe that there is a non-linear relationship between the upgrading of industrial structure and the high-quality development of economy. For example, Fan Qingquan and others (2020) found that the initial restraining effect of the upgrading of industrial structure on economic development gradually changed into promoting high-quality growth. Using panel data from 30 provinces in China from 2012 to 2017, Ren Xiaoyan and Yang Shuili (2020) found that industrial structure upgrading can significantly promote high-quality economic development, and their impacts have 
significant regional heterogeneity. Zhang Rui et Al. (2020) found that the high-quality development in the Yellow River basin was significantly driven by the upgrading of industrial structure, and the impact of the rationalization of industrial structure on the high-quality development was significantly different due to different urban types. Some scholars also believe that industrial structure upgrading plays an intermediary role in the impact of high-quality economic development, such as Li Taiping and Gu Yunan (2021) using panel data from nine provinces and two cities in the Yangtze River economic belt from 2007 to 2016, in the relationship between strategic emerging industrial agglomeration and the economic growth of the Yangtze River economic belt, the upgrading of industrial structure plays an intermediary role.

In summary, scholars now explore the relationship between the digital economy, the upgrade of the industrial structure, and the high quality development of the economy, the functional relationship among them has not been investigated under the unified analytical framework. The digital economy has an impact on the upgrading of industrial structure, and the upgrading of industrial structure will also affect the high-quality development of economy. Therefore, this paper holds that, there is a positive transmission mechanism between them: digital economy $\rightarrow$ industrial structure upgrade $\rightarrow$ high-quality economic development".". In addition, although the existing literature is abundant, there are still some limitations: First, there are few studies on the impact of industrial structure upgrading on high-quality economic development; Second, there are few empirical studies on the impact of digital economy on high-quality economic development; third, there are few studies that include industrial structure upgrading in the relationship between digital economy and high-quality economic development. Therefore, this paper selects the provincial panel data from 2015 to 2019, and uses the fixed effect model and the intermediary effect model to investigate the interaction among the digital economy, the industrial structure upgrading and the high-quality economic development, in order to provide research ideas and policy references for the realization of China's high-quality economic development.

\section{Research Design}

\subsection{Model}

According to the previous studies, this paper holds that the influence of digital economy on high-quality economic development is realized through the upgrading of industrial structure. In order to identify the existence of this mechanism, this paper constructs two empirical models as follows: one, exploring the influence of digital economy on high-quality economic development. It examines the relationship between the digital economy and high quality economic development on the basis of controls on foreign direct investment, government intervention, human capital, and urbanization levels, and reports on benchmark regression results. The model settings are as follows:

$$
\mathrm{TFP}_{\mathrm{it}}=\mathrm{C}+\mathrm{a}_{0} \mathrm{DIE}_{\mathrm{it}}+\sum_{\mathrm{j}=1}^{\mathrm{n}} \mathrm{a}_{\mathrm{j}} \mathrm{Control}_{\mathrm{it}}^{\mathrm{j}}+\varepsilon_{\text {it }}
$$

Second, in order to further explore whether industrial structure upgrading plays an important role in the relationship between digital economy and high-quality economic development, this paper draws on the research of Wen Zhonglin et Al. (2004)[32], the model is set as follows:

$$
T F P_{i t}=C_{1}+\alpha_{01} D I E_{i t}+\sum_{j=1}^{n} \alpha_{0 j} \text { Control }_{i t}^{j}+\varepsilon_{i t}
$$




$$
\begin{aligned}
& U I S_{i t}=C_{2}+\alpha_{11} D_{I E}+\sum_{j=1}^{n} \beta_{1 j} \text { Control }_{i t}^{j}+\varepsilon_{i t}
\end{aligned}
$$

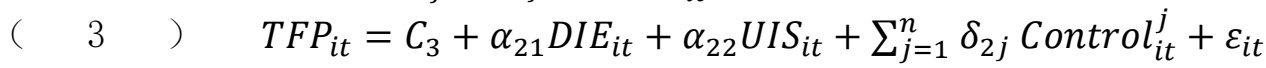

In formulas (1) to (4), subscript I and subscript $t$ represent provinces and years, c represents intercept terms, and it represents random perturbations. TFP is the high quality development level of economy, DIE is the development level of digital economy, UIS is the upgrading level of industrial structure, and as an mediation variable, Control is the control variable, this includes foreign direct investment, government intervention, human capital, and levels of urbanization.

The test procedure of the intermediary effect model is as follows: Step 1, regression analysis of equation (2), judgment of the influence of digital economy on high-quality economic development without intermediary variables, if 01 is significant, step 2, regression analysis of Equation (3), judgment of the influence of digital economy on the upgrading of industrial structure (11); step 3, evaluation of the influence of digital economy on the upgrading of industrial structure (11) ; The regression analysis of equation (4) verifies the direct effect (21) and the mediation effect (22) of the digital economy on the high-quality development of the economy. If both 11 and 22 are significant, then the mediation effect exists, if at least one of the 11 and 22 effects is not significant, it is necessary to carry out the second test, this second test is achieved by using Sobel statistics [33], and the formula for calculating the statistics is as follows:

$$
\mathrm{Zs}=\left(\alpha_{11} \times \alpha_{22}\right) / \sqrt{\alpha_{11}^{2} \times S_{\alpha 2}^{2}+\alpha_{22}^{2} \times S_{\alpha 11}^{2}}
$$

Among them, 11 is the regression coefficient in equation (2), 22 is the regression coefficient in equation (3), s 11 is the standard error of $11, \mathrm{~s} 22$ is the standard error of 22. In addition, the original hypothesis of Sobel mediation effect test is that the mediation effect is not significant, and the critical value of $Z$ value at $5 \%$ significance level is 0.97 .

\subsection{Variables}

\subsubsection{Explanatory Variable: High-Quality Economic Development}

Economic high-quality development is a pluralistic and comprehensive concept, its connotation is gradually expanded in practice, its essence is rich and multi-dimensional. The core of high-quality economic development is the new concept of development, the direction of guidance is innovation, the strategic goal is to build a modern economic system. The upgrading of the Total factor productivity, the satisfaction of the people's needs for a better life and the promotion of development through quality and efficiency are all important features of high-quality economic development. At the same time, high-quality economic development emphasizes the coordinated development of Economy, ecology and society. On the whole, high-quality economic development includes not only five economic categories, namely, stable economic development, optimization of economic structure, green economic development, efficient economic development and innovative economic development, and it embeds momentum, process, and results into high-quality economic development. Among them, in the process of economic development, what is required for the stability of people's production and life is stable economic development, and what is required for the adjustment of economic structure is the optimization of economic structure, green economic development is required to 
improve the mode of economic development, efficient economic development is required to improve the efficiency of economic development, and innovative economic development is required to ensure economic development. While the development of economic innovation reflects the motive force of economic development, the stable and efficient development of economy reflect the process of economic development, the green development of economy and the optimization of economic structure reflect the result of economic development. At present, there is no consensus in the existing literature on how to measure high-quality economic development. Some scholars have constructed an indicator system, while others have adopted single indicators such as per capita GDP, other scholars use total factor productivity to measure the level of high quality economic development, which includes input and output indicators Total factor productivity. The report to the 19th national congress of the communist party of china on promoting qualitative, efficiency and dynamic changes in China's economic development was submitted to the 19th national congress of the total factor productivity. The total factor productivity is a more comprehensive and objective measure of economic efficiency than other measures. In addition, considering the availability and completeness of data, this paper uses Liu Bo et Al. (2021)[34] as a reference to use total factor productivity to indicate the level of economic development with high quality and TFP as a marker. The above data comes from the China Statistical Yearbook.

\subsubsection{Explanatory Variable: Digital Economy}

As a brand-new economic form, digital economy appears after agricultural economy and industrial economy. It was first proposed in 1995 by Tapscott, a prominent scholar in American economics. The digital economy is different from the traditional economy in that the presentation of information flow in the traditional economy is entity, and the presentation of information flow in the digital economy is digital. The G20 Digital Economy Development and Cooperation Initiative adopted at the G20 Hangzhou Summit defines the digital economy as one in which the key factor of production is digitized knowledge and information, and its important carrier is modernized information network, its important driving force is ICT, and the effective use of ICT can enhance efficiency and promote economic structural optimization. It is a relatively common definition of the digital economy. With the development of digital economy, its extension is also evolving. This can be explained in a narrow and a broad sense. In a narrow sense, the new factors of production in the digital economy are a lot of digital information produced through the application of digital technology. Production and management are all centered around digital information, so that the value of data and information can be fully released, so that the economic development depends on the new driving force into the digital economy. In essence, digital economy mainly refers to "digital industrialization" , which includes market-oriented applications and information and communication industries. In a broad sense, digital economy includes not only "digital industrialization" , but also "industrial digitalization" . In other words, the digital economy includes the two parts of digital industrialization and industrial digitalization. Among them, the digitalization of industry is the digitalization of industry. Industrial digitalization is an economic process in which digital technology and industry are integrated and efficiency is improved. In this process, the efficient use of digital technology and the full acquisition of data and information, on the one hand, can make the production and operation efficiency of traditional industries greatly improved, on the other hand, the production cost and risk of micro-subject are effectively reduced. The digital 
economy is a series of economic activities which take the network as the important carrier, take the data as the key factor of production and take the information and communication technology as the important impetus. In addition, the core features of the digital economy include virtualized data, ICT clusters with strong penetration and integrated innovation, digital infrastructure with interconnectivity of all things, and disruptive innovation of digital technology clusters and their applications. At present, there are few researches on the measurement of digital economy, and there is no unified standard on how to measure digital economy. Therefore, considering the existing research context, this paper uses the research of Zhang Teng et al (2021) [35] , and uses the digital pratt \& whitney financial index to measure the development level of China's regional digital economy, the number, it was compiled by Peking University's Digital Finance Research Center in collaboration with the Ant Financial, and is marked by a DIE. The index is compiled on the basis of big data from Ant Financial trading accounts, while scientific calculations are made using methods including dimensionless quantification, coefficient of variation weighting and index composition, so its authenticity, credibility and authority is strong. Among them, the evaluation index system of digital economy development includes 3 first-level dimensions, they are use depth, support service degree and cover breadth respectively. The data comes from the "Peking University Digital Pratt \& Whitney Financial Index" Project Group.

\subsubsection{Intermediary Variable: Industrial Structure Upgrade}

The upgrade of industrial structure is a process in which the status and relationship of each industry in the industrial structure are transformed to a higher and more coordinated level. Generally speaking, industrial structure upgrading follows certain objective laws, that is to say, it is a process of industrial structure transition from low level to high level. The direct result of the upgrading of the industrial structure is the decrease of the proportion of the primary sector of the economy and the increase of the secondary and tertiary industries. The upgrading of industrial structure may be caused by the change of comparative advantage, factor endowment, technological progress and the change of the structure of commodity demand. In this respect, the result of the upgrading of industrial structure is affected by multiple factors, rather than a shift in an economic element. The upgrading of industrial structure mainly includes the rationalization of industrial structure and the upgrading of industrial structure. The rationalization of industrial structure refers to the rationality of the proportion between industries and reflects the coupling degree of input-output of factors. If the coupling degree between the allocation and the output ratio is higher, the industrial structure is more reasonable; otherwise, the industrial structure is more unreasonable. The upgrading of industrial structure refers to the evolution of industrial structure and reflects the development speed among industries. The higher the evolution degree of industrial structure, the higher the advanced level of industrial structure, and the lower the advanced level of industrial structure. At present, there are many measure indexes about industrial structure upgrading. Generally speaking, the upgrading of industrial structure can be described by the change of relative scale among industries. Among them, the important characteristic of industrial structure upgrade is the service of economic structure. The service upgrading of the economic structure can be better reflected in the ratio of tertiary sector of the economy output to secondary sector of the economy output. Therefore, this paper uses the ratio of the tertiary sector of the economy value added to the secondary sector of the economy value added to measure the upgrading of industrial 
structure, and uses the UIS mark. The above data comes from the China Statistical Yearbook.

\subsubsection{Control Variable}

In order to control the influence of other factors, referring to relevant theories, this paper draws on the research of Zheng Jialin and Xu Wenhua (2020), Ge Heping and Wu Fuxiang (2021), Zhang Yan (2021), Zhang Chao and Zhong Changbiao (2021), the control variables selected included foreign direct investment, government intervention, human capital, and urbanization levels. After the influx of foreign direct investment, the level of competition in China's domestic market will be affected by it, prompting high-tech enterprises to continuously improve product quality and technical level, while low-tech enterprises will be eliminated by the market, thereby affecting high-quality economic development. The government financial system of our country is special. The government has a strong motivation to intervene in the economic development, and this motivation plays an important role in the process of high-quality economic development. The impact of government intervention on high-quality economic development is different in different periods, and it can be divided into two stages: the first stage is the transition period of high-quality economic development, and it is difficult to solve the problems arising from the various aspects it covers, the second stage is a mature period of high-quality economic development. Awareness of environmental and ecological capital protection has been established, and stable economic growth has been achieved, government intervention at this time had a negative impact on high-quality economic development. Therefore, whether the first stage or the second stage, government intervention will affect the quality of economic development. Innovation is not only an important driving force for achieving high-quality economic development, but also a source of economic growth. And human is the main body of innovation, so the level of human capital can have an important impact on the high-quality development of a country's economy. The impact of urbanization on high-quality economic development is mainly reflected in: On the one hand, the urbanization process can affect high-quality economic development through the accumulation of knowledge and technology and human capital; on the other hand, the level of urbanization promotes the transfer of surplus labor from the countryside to the cities, promotes the upgrading of industrial structure, and thus affects the high-quality development of economy. In terms of measurement methods, the foreign direct investment is measured by the ratio of real foreign direct investment to GDP, the degree of government intervention is measured by the ratio of local fiscal expenditure to GDP, and the level of human capital is measured by the average years of schooling, urbanization is measured by the proportion of urban population to total population, which is identified by FDI, Gov, HUC and URB. The related control variables and data sources are shown in Table 1, in which the variables that can not be obtained directly are collated and calculated according to the related basic data. 
Table 1.Description of Control Variables and Data Sources

\begin{tabular}{|c|c|c|c|c|}
\hline \\
\hline $\begin{array}{l}\text { variable } \\
\text { name }\end{array}$ & $\begin{array}{l}\text { variable } \\
\text { symbol }\end{array}$ & $\begin{array}{l}\text { measurement } \\
\text { method }\end{array}$ & compute formula & data source \\
\hline $\begin{array}{c}\text { foreign } \\
\text { direct } \\
\text { investment }\end{array}$ & FDI & $\begin{array}{l}\text { Foreign direct } \\
\text { investment as a } \\
\text { share of GDP }\end{array}$ & $\begin{array}{l}\text { Actual utilization of } \\
\text { foreign direct } \\
\text { investment/GDP }\end{array}$ & $\begin{array}{r}\text { 《China } \\
\text { Statistical } \\
\text { Yearbook》 }\end{array}$ \\
\hline $\begin{array}{l}\text { governme } \\
\mathrm{nt} \\
\text { interventio } \\
\mathrm{n}\end{array}$ & GOV & $\begin{array}{l}\text { Local fiscal } \\
\text { expenditure as a } \\
\text { share of GDP }\end{array}$ & Local expenditure/GDP & $\begin{array}{c}\text { 《China } \\
\text { Statistical } \\
\text { Yearbook》 }\end{array}$ \\
\hline $\begin{array}{l}\text { human } \\
\text { capital }\end{array}$ & HUC & $\begin{array}{l}\text { Average years of } \\
\text { schooling }\end{array}$ & $\begin{array}{c}\text { (Number of illiterate } \\
\text { persons } \times 1+\text { Number of } \\
\text { primary school graduates } \\
\times 6+\text { Number of persons } \\
\text { with junior secondary } \\
\text { education } \times 9+\text { Number of } \\
\text { students with high school } \\
\text { and Technical Secondary } \\
\text { Education } \times 12+\text { Number of } \\
\text { college graduates or } \\
\text { above } \times 16) / \text { Total } \\
\text { population over } 6 \text { years of } \\
\text { age }\end{array}$ & $\begin{array}{c}\text { 《China } \\
\text { Statistical } \\
\text { Yearbook》 }\end{array}$ \\
\hline $\begin{array}{l}\text { level of } \\
\text { urbanizati } \\
\text { on }\end{array}$ & URB & $\begin{array}{c}\text { Urban population as } \\
\text { share of GDP }\end{array}$ & $\begin{array}{l}\text { Urban population/total } \\
\text { population }\end{array}$ & $\begin{array}{c}\text { 《China } \\
\text { Statistical } \\
\text { Yearbook } 》\end{array}$ \\
\hline
\end{tabular}

\subsection{Data Sources and Descriptive Statistics}

The data selected in this paper are panel data of 31 provinces in China from 2015 to 2019. Among them, the proxy variable of high quality economic development, total factor productivity, comes from the China Statistical Yearbook The original data of digital economy, industrial structure upgrade, foreign direct investment, government intervention, human capital and urbanization level are from the "Pratt \& Whitney Index of Peking University" and "China Statistical Yearbook" . Descriptive statistics for each variable are shown in Table 2.

The change rule of each variable can be preliminarily reflected by descriptive statistical analysis. Whereas the eastern, middle and western regions of China include: Beijing, Tianjin, Hebei, Liaoning, Shanghai, Jiangsu, Zhejiang, Fujian, Shandong, Guangdong, Hainan and 11 provinces; The middle region includes: Shanxi, Jilin, Heilongjiang, Anhui, Jiangxi, Henan, Hubei, Hunan and other eight provinces; The western region includes 12 provinces including Sichuan, Chongqing, Guizhou, Yunnan, Tibet, Shaanxi, Gansu, Qinghai, Ningxia, Xinjiang, Guangxi and Inner Mongolia. There are differences in economic and social development, and table 2 reports the mean values of all the variables for each region in the east, middle and west. Table 2 shows that high-quality economic development and the level of development of the digital economy fluctuate widely. Among them, the national average level of high-quality economic development is 1.729 , the average values of the eastern, middle and western regions are 1.681,1.653 and 1.804 respectively, and the national average value of the development level of digital economy is 269.269 , the mean value in the eastern region was 286.287 , which was significantly larger than that 
in the middle region (261.521) and in the western region (252.142). From this, we can know that there are obvious regional differences between the high-quality development of our economy and the development level of digital economy. Other relevant variables, such as foreign direct investment, government intervention, human capital, urbanization level and industrial structure upgrading of mediation variables also have significant regional differences.

Table2.Descriptive Statistics for Each Variable

\begin{tabular}{|c|c|c|c|c|c|c|c|}
\hline \multirow{3}{*}{ variable } & \multicolumn{4}{|c|}{ mean value } & \multirow{3}{*}{$\begin{array}{c}\text { standard } \\
\text { deviation }\end{array}$} & \multirow{3}{*}{$\begin{array}{l}\text { minimum } \\
\text { value }\end{array}$} & \multirow{3}{*}{$\begin{array}{l}\text { maximum } \\
\text { value }\end{array}$} \\
\hline & $\begin{array}{l}\text { whole } \\
\text { country }\end{array}$ & $\begin{array}{l}\text { eastern } \\
\text { region }\end{array}$ & $\begin{array}{l}\text { middle } \\
\text { region }\end{array}$ & $\begin{array}{c}\text { western } \\
\text { region }\end{array}$ & & & \\
\hline & $\mathrm{N}=155$ & $\mathrm{~N}=55$ & $\mathrm{~N}=40$ & $\mathrm{~N}=60$ & & & \\
\hline TFP & 1.729 & 1. 681 & 1.653 & 1.804 & 0.729 & 0.193 & 2.900 \\
\hline DIE & 269. 269 & 286. 287 & 261.521 & 252. 142 & 47.696 & 186.380 & 410.280 \\
\hline UIS & 1.456 & 1.671 & 1.203 & 1.319 & 0.738 & 0.801 & 5.234 \\
\hline FDI & 0.012 & 0.015 & 0.015 & 0.005 & 0.013 & 0.000 & 0.078 \\
\hline GOV & 0.159 & 0.129 & 0.148 & 0.194 & 0.141 & 0.003 & 0.627 \\
\hline HUC & 9.151 & 9.759 & 9.210 & 8.436 & 1.135 & 5.063 & 12.782 \\
\hline URB & 0.785 & 0.671 & 0.556 & 1.018 & 2.437 & 0.277 & 30.900 \\
\hline
\end{tabular}

\section{Empirical Results and Analysis \\ 4.1.Correlation Analysis and Stationarity Test}

Before doing regression analysis, in order to avoid the false regression caused by the existence of unit root and the distortion of model estimation caused by multicollinearity. Therefore, this article needs to carry on the correlation analysis and the stationarity test to each variable first. The unit root test is the most commonly used method in the stationarity test. Table 3 shows that the correlation coefficient between most variables is less than 0.7. At the same time, the variance expansion factor between the variables is calculated, the VIF value of each variable is lower than 10 , so the problem of the multicollinearity between the model variables does not exist.

Table3.Correlation Analysis of Variables

\begin{tabular}{|c|c|c|c|c|c|c|c|}
\hline variable & DIE & UIS & FDI & GOV & HUC & URB & VIF value \\
\hline DIE & 1.0000 & 0.3508 & -0.2373 & -0.6311 & 0.4203 & -0.0139 & 0.4241 \\
\hline UIS & 0.3508 & 1.0000 & 0.1728 & -0.0220 & 0.5553 & 0.0414 & 0.6271 \\
\hline FDI & -0.2373 & 0.1728 & 1.0000 & 0.3580 & 0.3174 & -0.0364 & 0.6981 \\
\hline GOV & -0.6311 & -0.0220 & 0.3580 & 1.0000 & -0.1180 & 0.0268 & 0.5301 \\
\hline HUC & 0.4203 & 0.5553 & 0.3174 & -0.1180 & 1.0000 & -0.2127 & 0.4869 \\
\hline URB & -0.0139 & 0.0414 & -0.0364 & 0.0268 & -0.2127 & 1.0000 & 0.9104 \\
\hline
\end{tabular}

Table 4 shows the results of unit root tests for each variable. Both HT test and ADF test are used to determine the stationarity of data. The original assumptions of HT test and ADF test are unit roots. The results in table 4 show that each variable rejects the original hypothesis under these two tests, that is, all variables are stationary. To do this, you can further regress the data. 
Table4.Panel Data Unit Root Test

\begin{tabular}{|c|c|c|c|c|c|}
\hline variable & HT test & P value & ADF test & P value & test result \\
\hline TFP & $0.2521^{* * *}$ & 0.0023 & $-5.5678^{* * *}$ & 0.0000 & stable \\
\hline DIE & $1.0169^{* * * *}$ & 0.0000 & $1.1153^{* * *}$ & 0.0000 & stable \\
\hline UIS & $0.7307^{*}$ & 0.0995 & $-5.5425^{* * *}$ & 0.0056 & stable \\
\hline FDI & $0.5401^{* *}$ & 0.0476 & $0.2808^{* * *}$ & 0.0000 & stable \\
\hline GOV & $0.6645^{*}$ & 0.0969 & $0.0000^{* * *}$ & 0.0000 & stable \\
\hline HUC & $0.3731^{* * *}$ & 0.0073 & $1.1217^{* * *}$ & 0.0000 & stable \\
\hline URB & $-0.3329^{* * * *}$ & 0.0000 & $0.0000^{* * *}$ & 0.0001 & stable \\
\hline
\end{tabular}

Note: $* * *$ And $* * *$ Were significant at $10 \%, 5 \%$ and $1 \%$ significance levels, respectively.

\subsection{Regression Analysis of the Influence of Digital Economy on High-Quality Economic Development}

Table 5 reports the results of the benchmark regression on the impact of the digital economy on high-quality economic development. Among them, the model (1) is an empirical test of the impact of digital economy on high-quality economic development under the national sample, and the model (2) is an empirical test of the impact of digital economy on high-quality economic development in the eastern region, model (3) is an empirical test of the impact of digital economy on high-quality economic development in central China, and model (4) is an empirical test of the impact of digital economy on high-quality economic development in western China. According to the results of hausman test, the fixed-effect model is more reasonable in this paper. At the same time, in order to alleviate the statistical inference and heteroscedasticity problems caused by cross-section correlation, the model needs to be modified by using the Driscoll-Kraay standard error. The results of Table 5 show that the regression coefficients of each variable show a high consistency, which reflects that the regression results of the model are robust. From the fitting results of the model (1) to the model (4) in Table 5, we can see that the regression coefficients of the digital economy to the high-quality economic development are $0.0089,0.0143,0.0137$ and 0.0098 respectively, and all of them have passed the significant test, it shows that the promotion of the development level of digital economy can promote the high-quality development of regional economy. At the same time, the foreign direct investment also played a certain role in promoting the high-quality development of the regional economy; The improvement of human capital level can also promote the high-quality development of regional economy, and the improvement of urbanization level can help the high-quality development of regional economy. It is worth noting that the digital economy can promote high-quality economic development, and it shows significant regional heterogeneity. The Eastern, central and western regions are the order of its promotion from strong to weak. The Eastern, central and western areas of China's digital economy development level from high to the end of the sequence. That is to say, the strength of promoting effect of digital economy on high-quality economic development is proportional to the development level of regional digital economy. The reason may be that the midwestern sectional figure skating championships has a relatively low level of development in the digital economy compared with the eastern region, and the application of midwestern sectional figure skating championships technology is mainly concentrated at low levels, such as in the fields of life services and production, etc. , the eastern region has further integrated the digital economy with the real economy, as a result, the driving force of the digital economy in eastern China is stronger than that of the midwestern sectional figure skating championships. 
Table5.Impact of Digital Economy on High-Quality Economic Development

\begin{tabular}{|c|c|c|c|c|}
\hline \multirow{3}{*}{ variable } & national sample & eastern region & middle region & western region \\
\hline & TFP & TFP & TFP & TFP \\
\hline & (1) & (2) & (3) & (4) \\
\hline DIE & $\begin{array}{c}0.0089^{* * *} \\
(5.72)\end{array}$ & $\begin{array}{c}0.0143^{* * *} \\
(3.29)\end{array}$ & $\begin{array}{c}0.0137^{* * *} \\
(4.84)\end{array}$ & $\begin{array}{c}0.0098^{* * *} \\
(3.51)\end{array}$ \\
\hline FDI & $\begin{array}{l}7.2605^{*} \\
(1.68)\end{array}$ & $\begin{array}{c}1.8697^{\text {** }} \\
(2.20)\end{array}$ & $\begin{array}{c}11.5731^{*} \\
(1.65)\end{array}$ & $\begin{array}{c}8.4168^{* * *} \\
(2.59)\end{array}$ \\
\hline GOV & $\begin{array}{c}-0.1346^{*} \\
(-1.68)\end{array}$ & $\begin{array}{c}-0.5910^{*} \\
(-1.67)\end{array}$ & $\begin{array}{c}-0.6132^{*} \\
(-1.93)\end{array}$ & $\begin{array}{c}-0.3381^{*} \\
(-1.69)\end{array}$ \\
\hline $\mathrm{HUC}$ & $\begin{array}{c}0.0774^{* *} \\
(1.96)\end{array}$ & $\begin{array}{l}0.2257^{*} \\
(1.71)\end{array}$ & $\begin{array}{l}0.6239^{*} \\
(1.66)\end{array}$ & $\begin{array}{c}0.0090^{* *} \\
(2.11)\end{array}$ \\
\hline URB & $\begin{array}{l}0.0223^{*} \\
(1.87)\end{array}$ & $\begin{array}{l}4.2627^{* *} \\
(2.28)\end{array}$ & $\begin{array}{l}4.6634^{*} \\
(1.64)\end{array}$ & $\begin{array}{c}0.0267^{\text {** }} \\
(1.98)\end{array}$ \\
\hline _cons & $\begin{array}{c}-0.1261^{* * *} \\
(-2.63)\end{array}$ & $\begin{array}{c}-0.4059^{* * *} \\
(-2.84)\end{array}$ & $\begin{array}{c}-5.5000^{* * *} \\
(-3.19)\end{array}$ & $\begin{array}{c}-1.6156^{* * *} \\
(-2.85)\end{array}$ \\
\hline $\mathrm{R}^{2}$ & 0.6411 & 0.7180 & 0.6443 & 0.7404 \\
\hline $\mathrm{N}$ & 155 & 55 & 40 & 60 \\
\hline $\begin{array}{c}\text { model } \\
\text { selection }\end{array}$ & $\mathrm{FE}$ & $\mathrm{FE}$ & $\mathrm{FE}$ & $\mathrm{FE}$ \\
\hline hausman value & 28.38 & 28.38 & 28.38 & 28.38 \\
\hline $\mathrm{P}$ value & 0.0000 & 0.0000 & 0.0000 & 0.0000 \\
\hline
\end{tabular}

Note: (1) the values in parentheses represent t statistics, (2) $*, * *, * * *$ are significant at $10 \%, 5 \%$, and $1 \%$ significance levels, respectively.

\subsection{Analysis on the Intermediary Effect of Industrial Structure Upgrade under the National Sample}

With regard to the promotion of digital economy to high-quality economic development and regional heterogeneity determined, in order to further examine whether industrial structure upgrading plays a role in the impact of digital economy on high-quality economic development, therefore, this paper carries on the mediation effect test, in which the mediation variable is the industrial structure upgrade.

Table6.Mediation Effect of Industrial Structure Upgrade in China

\begin{tabular}{|c|c|c|c|}
\hline \multirow{2}{*}{ variable } & TFP & UIS & TFP \\
\cline { 2 - 4 } & Step one & Step Two & Step three \\
\hline DIE & $0.0089^{* * *}$ & $0.0021^{* * *}$ & $0.0088^{* * *}$ \\
& $(5.72)$ & $(12.16)$ & $0.1160^{*}$ \\
\hline UIS & - & - & $(1.66)$ \\
\hline FDI & $7.2605^{*}$ & $-7.3157^{* * *}$ & $-18.1108^{* * *}$ \\
& $(1.68)$ & $(-9.86)$ & $(-4.32)$ \\
\hline GOV & $-0.1346^{*}$ & $-0.4914^{* * *}$ & $-1.9237^{* * *}$ \\
& $(-1.68)$ & $(-7.08)$ & $(-4.96)$ \\
\hline HUC & $0.0774^{* *}$ & $0.3385^{* * *}$ & $-0.0015^{* *}$ \\
\hline
\end{tabular}




\begin{tabular}{|c|c|c|c|}
\hline & $(1.96)$ & (6. 45) & $(-2.02)$ \\
\hline URB & $\begin{array}{l}0.0223^{*} \\
(1.87)\end{array}$ & $\begin{array}{l}0.0011^{\text {** }} \\
(2.23)\end{array}$ & $\begin{array}{l}0.0278^{*} \\
(1.86)\end{array}$ \\
\hline _cons & $\begin{array}{c}-0.1261^{* * *} \\
(-2.63)\end{array}$ & $\begin{array}{l}2.0363^{* * *} \\
(24.73)\end{array}$ & $\begin{array}{l}0.1261^{* * *} \\
(8.23)\end{array}$ \\
\hline $\mathrm{R}^{2}$ & 0.6411 & 0.5870 & 0.7774 \\
\hline $\mathrm{N}$ & 155 & 155 & 155 \\
\hline $\begin{array}{c}\text { model } \\
\text { selection }\end{array}$ & $\mathrm{FE}$ & $\mathrm{FE}$ & $\mathrm{FE}$ \\
\hline Hausman test & 28.38 & 25.79 & 34.16 \\
\hline $\mathrm{P}$ value & 0.0000 & 0.0000 & 0.1356 \\
\hline mediation effect test & \multicolumn{3}{|c|}{$\begin{array}{l}\text { Sobel test: } Z=3.8878^{* * *} \\
\text { mediation effect significant } \\
\text { ortion of mediation effect }=25.17 \%\end{array}$} \\
\hline
\end{tabular}

Note: (1) the values in parentheses represent $\mathrm{t}$ statistics, $(2) *, * *, * * *$ are significant at $10 \%, 5 \%$, and $1 \%$ significance levels, respectively.

Table 6 shows that the first step is an empirical test of the overall impact of the digital economy on high-quality economic development, which is the same as the regression result of model (1). The impact coefficient of the digital economy is positive and significant, the second step is to test the influence of the digital economy on the upgrade of industrial structure, the influence coefficient of the digital economy is positive, and the significance level test of $1 \%$ is passed, the third step is to test the impact of digital economy and industrial structure upgrade on high-quality economic development, it is found that the upgrade of industrial structure can significantly promote high-quality economic development. Moreover, the regression coefficient of the digital economy in the third step is significantly lower than that in the first step, it shows that industrial structure upgrade plays an important role in the process of digital economy promoting high-quality economic development, and industrial structure upgrade is the key factor of digital economy boosting regional economic high-quality development. The observation coefficient shows that for every unit of improvement in the digital economy, the upgrade of the industrial structure can increase by 0.0021 units, while for every unit of improvement in the industrial structure, high-quality economic development can increase by 0.1160 units, that is to say, for each unit of upgrade the digital economy, the upgrade of the industrial structure can promote the high-quality development of the economy by 0.0002 units, and the proportion of mediation effect is $25.17 \%$. In other words, $25.17 \%$ of the impact of the digital economy on high-quality economic development is achieved through upgrade the industrial structure. In addition, the value of Sobel statistic as a robustness test is larger than the critical value at 5\% significance level, which shows that the test result of mediation effect is robust.

\subsection{An Analysis of the Intermediary Effect of Industrial Structure Upgrade in East, Middle and West China}

China is a large country with a gradient pattern of economic and social development in the eastern, middle and western regions. There are also great differences in the development level of regional digital economy, the upgrade level of industrial structure and the high-quality development of economy. Therefore, in order 
to make the research conclusion more targeted and scientific, this paper further empirically tests the mediation effect of industrial structure upgrade in sub-regions.

The first step in Table 7 is an empirical test of the impact of the digital economy on high-quality economic development in each region, which is the same as the regression results in table 5. It focuses on the process of testing the mediation effect of industrial structure upgrade. According to the test results of the second step, the digital economy can significantly promote the upgrading level of regional industrial structure, and its effect intensity is gradually strengthened from east to west. According to the test results of the third step, compared with the regression results of the first step, the regression coefficient of the digital economy in each region decreases when the industrial structure upgrade is used as the intermediary variable. According to the size of the mediation effect of industrial structure upgrade, $36.72 \%$ of the impact of digital economy on high-quality economic development in eastern China is transmitted by industrial structure upgrade, $24.03 \%$ of the influence of the digital economy on the high-quality economic development in the central region is transmitted by the upgrade of the industrial structure, while $48.57 \%$ of the influence of the digital economy on the high-quality economic development in the western region is transmitted by the upgrade of the industrial structure. Table 7 shows that high-quality economic development in the western region has benefited more from the upgrading of industrial structure brought about by the digital economy, followed by the eastern region and the central region at least. The reason for this phenomenon can be explained by the process of testing the mediation effect. The digital economy plays a significant role in promoting the upgrade level of industrial structure, but the influence of industrial structure upgrade on the high-quality development of regional economy has regional heterogeneity. According to the test results of the third step, the promotion of industrial structure upgrade to high-quality economic development is strongest in the eastern region, followed by the western region, and finally in the central region. Therefore, the reason why the industrial structure upgrade accounts for a low proportion in the middle region is that it has not effectively supported the high-quality economic development, and more actual economic benefits have not been created and exerted.

Table7.Mediation Effect Test of Industrial Structure Upgrade in East, Middle and West China

\begin{tabular}{|c|c|c|c|c|c|}
\hline \multirow[t]{2}{*}{ region } & \multirow[t]{2}{*}{ variable } & TFP & UIS & TFP & test result \\
\hline & & step one & step two & step three & \multirow{6}{*}{$\begin{array}{c}\text { Sobeltest: } \\
\mathrm{Z}=4.6401^{* * *} \\
\text { mediation } \\
\text { effect significant } \\
\text { mediation } \\
\text { effect/total } \\
\text { effect }=36.72 \%\end{array}$} \\
\hline \multirow{5}{*}{$\begin{array}{c}\text { eastern } \\
\text { region }\end{array}$} & DIE & $\begin{array}{c}0.0143^{\text {**** }} \\
(3.29)\end{array}$ & $\begin{array}{c}0.0024^{* * * *} \\
(8.74)\end{array}$ & $\begin{array}{l}0.0084^{* * * *} \\
(4.51)\end{array}$ & \\
\hline & UIS & - & - & $\begin{array}{l}0.3877^{*} \\
(1.93)\end{array}$ & \\
\hline & Controls & Yes & Yes & Yes & \\
\hline & $\mathrm{R}^{2}$ & 0.6534 & 0.6444 & 0.8237 & \\
\hline & & $\mathrm{FE}$ & FE & FE & \\
\hline & DIE & $\begin{array}{c}0.0137^{* * * *} \\
(4.84)\end{array}$ & $\begin{array}{l}0.0284^{* *} \\
(2.44)\end{array}$ & $\begin{array}{c}0.0096^{* * *} \\
(4.29)\end{array}$ & Sobel test: \\
\hline & UIS & - & - & $\begin{array}{l}0.0799 \\
(0.98)\end{array}$ & $Z=1.127$ \\
\hline middle & Controls & Yes & Yes & Yes & mediation effect \\
\hline region & $\mathrm{R}^{2}$ & 0.5302 & 0.6919 & 0.8106 & \\
\hline
\end{tabular}




\begin{tabular}{|c|c|c|c|c|c|}
\hline & $\begin{array}{c}\text { model } \\
\text { selection }\end{array}$ & $\mathrm{FE}$ & $\mathrm{FE}$ & $\mathrm{FE}$ & $\begin{array}{c}\text { mediation } \\
\text { effect } / \text { total } \\
\text { effect }=24.03 \%\end{array}$ \\
\hline \multirow{5}{*}{$\begin{array}{c}\text { western } \\
\text { region }\end{array}$} & DIE & $\begin{array}{c}0.0098^{* * *} \\
(3.51)\end{array}$ & $\begin{array}{c}0.0412^{* * *} \\
(3.89)\end{array}$ & $\begin{array}{c}0.0026^{* * *} \\
(6.66)\end{array}$ & \multirow{5}{*}{$\begin{array}{c}\text { Sobel test: } \\
Z=2.1944^{* * *} \\
\text { mediation effect } \\
\text { significant } \\
\\
\text { mediation } \\
\text { effect } / \text { total effec } \\
=48.57 \%\end{array}$} \\
\hline & UIS & - & - & $\begin{array}{l}0.1598 \\
(0.41)\end{array}$ & \\
\hline & Controls & Yes & Yes & Yes & \\
\hline & $\mathrm{R}^{2}$ & 0.7404 & 0.7252 & 0.7472 & \\
\hline & $\begin{array}{c}\text { model } \\
\text { selection }\end{array}$ & $\mathrm{FE}$ & $\mathrm{FE}$ & $\mathrm{FE}$ & \\
\hline
\end{tabular}

Note: (1) the values in parentheses represent t statistics, (2) $*, * *, * * *$ are significant at $10 \%, 5 \%$, and $1 \%$ significance levels, respectively.

\section{Conclusions and Policy Recommendations \\ 5.1.Conclusions}

Based on the provincial panel data from 2015 to 2019, this paper investigates the impact of digital economy on high-quality economic development and the intermediary role of industrial structure upgrade in the relationship between them. The regression results show that the digital economy plays a significant role in promoting the high-quality development of China's economy. At the same time, the impact of digital economy on high-quality economic development in the central and western regions is obviously lower than that in the eastern region. In addition, digital economy can indirectly promote the high-quality development of regional economy through the upgrade of industrial structure, but the mediation effect of industrial structure upgrade is relatively low, and there are certain regional differences, the mediation effect of industrial structure upgrade in the western region is stronger than that in the eastern and middle regions.

\subsection{Policy Recommendations}

Based on the above empirical test results, in order to better accelerate the development of China's digital economy and upgrade the level of industrial structure to promote high-quality economic development, this paper puts forward the following policy recommendations:

First, the promotion of digital economy to high-quality economic development has been empirically tested in this paper. In the process of high-quality economic development, all regions should stimulate the promotion of digital economy to high-quality economic development, establish a data standard system to facilitate data flow and sharing. At the same time, to increase the core information technology research and develop investment, to build an Internet platform to achieve digital transformation.

Second, the development level of digital economy in different regions of China is quite different, and the impact on high-quality economic development is also different. While improving the level of digital economy development in the eastern region, it is necessary to introduce resources such as technology and information into the middle and western regions, so as to strengthen the role of digital economy in 
promoting high-quality economic development in the middle and western regions, in order to achieve coordinated development of regional economy.

Third, the upgrade of industrial structure is the effective transmission path of digital economy in high-quality economic development. On the one hand, the government should speed up the development of new industries, improve the efficiency and quality of new industries; on the other hand, it should cultivate new driving forces, change old ones into new ones, and speed up the development of information technology services, so as to achieve high-quality economic development.

\section{References}

1. Zhang Leisheng. Theoretical innovation of China's economic development in the New Era: A study of Xi Jinping's important exposition on high-quality Economic Development[J] .Theory and reform, 2020, (5) : 1-11.

2. Xie Xinshui. Who will become the leading country of digitalization: digitalization from industrialization[J].Theory and reform, 2021, (3) : 67-79.

3. Yang Jun, Fan Peng. Risk, challenge of new technological revolution and adaptive change of National Governance System[J].Foreign Social Sciences, 2020, (5) : 125-131.

4. Huang Ming, He Wan. A dialectical analysis of the platformization of digital labor[J]. Foreign Social Sciences, 2021, (2) : 48-56.

5. Wen Jun, Deng Peidong, Zhang Qianxiao. How does digital economy innovation reshape high-quality development path[J].Journal of the humanities, 2020, (11) : 93-103.

6. Sheng Lei.Digital economy leads to high-quality industrial development: Dynamic Mechanism, internal logic and implementation path[J].Price theory and practice, 2020, (2) : 13-17 + 34 .

7. Zhou Qingxiang,He Aiping.Digital Economy enables high-quality development in the Yellow River Basin [J] .Economic issues, 2020, (11) : 8-17.

8. Sheba.Mechanism and path of digital economy promoting high-quality development of urban economy[J].Journal of Xi'an Institute of Finance and Economics, 2020, (2) : 10-14.

9. Li Hui.Digital Economy drives the transition of enterprises to high quality development[J].Journal of Xi'an Institute of Finance and Economics, 2020, (2) : 25-29.

10. Wang Juan. Digital economy drives high-quality economic development: Factor Allocation and Strategic Choice [J]. Ningxia Social Sciences, 2019, (5) : 88-94.

11. Ding Zhifan. Mechanism of Digital Economy Driving high-quality economic development:a theoretical analysis framework[J].Discussion of modern economics, 2020, (1) : 85-92.

12. Yang Hutao.Growth efficiency of digital economy and high-quality development of Chinese economy[J].Research on socialism with Chinese characteristics, 2020, (3) : 21-32.

13. Wei Zhuangyu, Li Yiting, Wu Kedong. Can the digital economy promote the high-quality development of manufacturing industry? An empirical analysis on provincial panel data[J]. Wuhan Finance, 2021, (3) : 37-45.

14. Cheng Yiqiu.High-quality Development of Digital Economy Enable City -Analysis of quasi-natural experiment based on smart city construction[J].Price Theory \& Practice, 2020,(9) : 156-159+180. 
15. Ning Chaoshan.Digital Economy, factor marketization and high-quality Economic Development[J] . Journal of Changbai University, 2021, (1) : 114-120.

16. Zhao Tao, Jang Ji, Leung Sheungkwan. Digital Economy, Enterepreneurial activity and high-quality development: Empirical Evidence from Chinese Cities [J] . Managing the world, 2020, (10) : 65-76.

17. Zhang Yuzhe. Digital Economy drive industrial structure to the high-end development ideas and main tasks[J]. Economics in action, 2018, (9) : 85-91.

18. Lin Yuho, Chen Yingkwai. Digital Economy and upgrading of industrial structure: A spatial econometric test from the perspective of factor flow $[\mathrm{J}]$. Research in Business Economics, 2020, (9) : 172-175.

19. Li Xiaozhong, Wu Jiaxu.regional differences in industrial restructuring and upgrading driven by the digital economy[J]. International Economic Cooperation, 2020, (4) : 81-91.

20. Wang Kai. Digital Economy, resource allocation and upgrading of industrial structure[J]. Finance and economics, 2021, (4) : 57-65.

21. Chen Xiaodong, Yang Xiaoxia. Influence of Digital Economy Development on industrial structure upgrading:a study based on grey correlation entropy and dissipative Structure Theory[J] .Reform, 2021, (3) : 26-39.

22. Li Yingjie, Han Ping. The impact of Digital Economy Development on the optimization and upgrading of industrial structure in China: An empirical analysis based on provincial panel data[J].Research in Business Economics, 2021, (6) : 183-188.

23. Jiao Shuaitao, Sun Qiubi. Research on the influence of Digital Economy Development on industrial structure upgrading in China[J].Industrial Technology Economy, 2021, (5) : 146-154.

24. Shen Yunhong, Huang Heng. The impact of Digital Economy on the optimization and upgrading of manufacturing industry structure:A panel data from 2008 to 2017 in Zhejiang Province[J]. Research in science and Technology Management, 2020, (3) : 147-154.

25. He Daan, Xu Yifan. Digital Economy Operation and supply-side restructuring [J] .Economist, 2020, (4) : 57-67.

26. Zhu Fenghui and Liu Lifeng. Industrial Structure Upgrading and high-quality economic development in China:Based on empirical data of cities at and above prefecture level[J].Journal of the Yunnan University of Finance and Economics, 2020, (6) : 42-53.

27. Shi Dan, Li Peng, Xu Ming.Industrial restructuring and upgrading and high-quality Economic Development[J].Fujian Forum (humanities and Social Sciences Edition), 2020, (9) : 108-118.

28. Fan Qingquan, Chu Chengjun, Gao Jianing. Impact of environmental regulation and Industrial Structure Upgrading on high-quality Economic Development[J] . China's population, resources and environment, 2020, (6) : 84-94.

29. Ren Xiaoyan, Yang Shuili. Technological Innovation, Industrial Structure Upgrade and high-quality economic development: a measure analysis based on independence effect and synergy effect[J].East China economic management, 2020, (11): 72-80.

30. Zhang Rui, Wang Geyi, Summer Camp Sun. Fiscal decentralization, industrial structure and high-quality development of the Yellow River Basin[J].Economic Problems, 2020, (9) : 1-11.

31. Li Taiping, Gu Yunan. Strategic Emerging Industrial Agglomeration, industrial structure upgrade and high-quality development of regional economy: An 
empirical analysis based on the Yangtze River economic belt[J]. Journal of the Henan Normal University, 2021, (1) : 78-87.

32. Wen Zhonglin and others. Intermediate Effect Test Procedure and its application[J].Journal of Psychology, 2004, (5) : 614-620.

33. Sobel M E.Asymptotic confidence intervals for indirect effects in Structural Equation Models[J]. Sociological Methodology,1982,(13): 290-312.

34. Liu Bo, Hu Zongyi, Gong Zhimin. Financial Structure, R\&D Investment and High Quality Development of regional economy[J].Yunnan Social Sciences, 2021, (3) : 84-92.

35. Zhang Teng, Jiang Fu Xin, Wei Tao. Can Digital Economy become a new driving force to promote high-quality development of China's economy?[J].. Economic Exploration, 2021, (1) : 25-39.

36. $\mathrm{Wu}$ Zhenhua.Study on the threshold effect of technological innovation on industrial structure optimization[J].China Science and Technology Forum, 2021, (4) : $1-11$.

37. Zheng Jialin, Xu Wenhua. A study on the mechanism of digital economy boosting high-quality economic development in China:An analysis from the perspective of regional heterogeneity[J].Price theory and practice, 2020, (8) : 148-151.

38. Ge Heping,Wu Fuxiang.Digital economy enables high-quality economic development:Theoretical Mechanism and empirical evidence[J].Nanjing Social Sciences, 2021, (1) : 24-33.

39. Zhang Yan. Digital Economy, spillover and Total factor productivity[J]. Guizhou Social Sciences, 2021, (3) : 139-145.

40. Zhang Chao, Zhong Changbiao.Financial Innovation, industrial structure change and high-quality economic development[J].Kong Hon Forum, 2021, (4) : 5-16. 